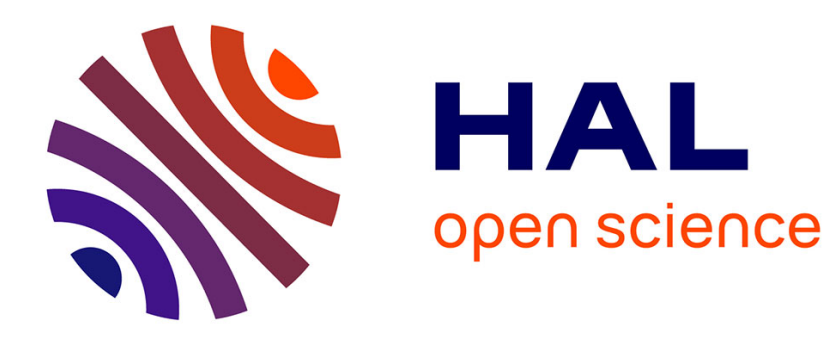

\title{
Thermomechanical Response of Aluminum to Pulsed Electron Beam
}

W. Tang, R. Zhang

\section{To cite this version:}

W. Tang, R. Zhang. Thermomechanical Response of Aluminum to Pulsed Electron Beam. Journal de Physique IV Proceedings, 1997, 07 (C3), pp.C3-623-C3-628. 10.1051/jp4:19973107 • jpa-00255391

\section{HAL Id: jpa-00255391 https://hal.science/jpa-00255391}

Submitted on 1 Jan 1997

HAL is a multi-disciplinary open access archive for the deposit and dissemination of scientific research documents, whether they are published or not. The documents may come from teaching and research institutions in France or abroad, or from public or private research centers.
L'archive ouverte pluridisciplinaire HAL, est destinée au dépôt et à la diffusion de documents scientifiques de niveau recherche, publiés ou non, émanant des établissements d'enseignement et de recherche français ou étrangers, des laboratoires publics ou privés. 


\title{
Thermomechanical Response of Aluminum to Pulsed Electron Beam
}

\author{
W. Tang and R. Zhang
}

Department of Applied Physics, National University of Defense Technology, Changsha, Hunan 410073, P.R. China

\begin{abstract}
When a powerful electron beam pulse interacts with a solid target, the surface layer will expand rapidly due to the large amount of energy absorbing, at the same time a thermal stress wave is generated in the target. In this paper, we calculate the energy deposition by using Monte Carlo methods, and calculate the wave propagation using the hydrodynamic equations. The equation of state (EOS) used in the calculation is the GRAY three phase EOS, all the calculation is performed by the computer program DRAMID. Based on a number of calculations, the wave propagation is discussed, the relations between the peak front surface blow-off velocity, specific mass loss as well as the impulse and incident fluence and electron energy for aluminum are presented.
\end{abstract}

\begin{abstract}
Résumé: Lorsque l'impulsion d'un faisceau d'électrons à haute énergie interagit avec une cible solide, la couche superficielle se dilate rapidement en raison de l'énergie absorbée importante; en même temps une onde de contrainte thermique est générée dans la cible. Dans cette publication on calcule le dépôt d'énergie en utilisant la méthode de Monte Carlo et la propagation des ondes à l'aide des équations en hydrodynamique. L'équation d'état utilisée dans le calcul est celle de GRAY (à trois phases). Tous les calculs ont été effectués sur le programme d'ordinateur DRAMID. La discussion sur la propagation des ondes est basée sur un certain nombre de calculs; Les relations entre la vitesse du front de propagation, la perte de masse spécifique ainsi que la fluence incidente et l'énergie des électrons sont présentées dans le cas de l'aluminium.
\end{abstract}

\section{INTRODUCTION}

A large amount of energy will deposit in the surface layer when a solid target is shined by a pulsed electron beam, the energy deposition rate can reach or over the order of $10^{10} \mathrm{Jcm}^{2} \mathrm{~s}^{-1}$. In the energy deposition region, the material is at high temperature and high pressure state, so a portion (or all) of the heated material will "blow-off" from the front of the target as vapor and/or liquid. By conservation of momentum an impulsive load is produced which is coupled to the remaining solid portion of the target, and, a thermal stress wave (i.e. stress pulse) is generated and propagates in the solid region.

In this paper, the thermomechanical response of aluminum to pulsed electron beam is studied numerically. In the simulation, the energy deposition is calculated using Monte Carlo methods, the thermomechanical response is calculated by solving simultaneously the equations of conservation conservation of mass, momentum, and energy, the thermodynamic states is described by the GRAY EOS [1], and all calculation is performed with our computer code DRAMID. 


\section{CALCULATION METHODS}

\subsection{Energy deposition}

When a high fluence and high-velocity electron beam irradiates a solid sample, the electrons will loss their kinetic energy by interactions with the atoms of the sample. The energy loss of the incident electrons is absorbed by the atoms and is converted into the thermal energy of the sample. We know from atomic physics, the interaction of a electron with a atom has the following four types: (1) non-elastic collision with electrons in the atom; (2) non-elastic collision with the nuclear; (3) elastic collision with electrons in the atom; (4) elastic collision with the nuclear. In general, the elastic collision effect can be neglected because the contribution of the elastic collision to energy deposition is very little.

For a given incident electron energy, we use Monte Carlo methods to calculate the electron energy loss by combining Moliere multiple scattering theory with the continuous slowing down energy loss approximation. The electron histories are followed until their energy degrades to $8 \mathrm{keV}$. Corrections for bremsstrahlung and density effects are also included, as well as back scattering losses. For a detailed description of the method, the reader may refer to Berger's original literature [2]

\subsection{Equation of state}

A sample may melt or vaporize when a large amount of energy deposited in it, so we employ the GRAY EOS to describe the thermodynamic states of the material. The basic idea of the GRAY EOS is to divide the state into two large regions, i.e. solid-liquid and liquid-vapor. In the solid-liquid region, the state is divided into following four phases: solid, melt, liquid and hot liquid, and the scaling law model of liquid metal is used. In the liquid-vapor region, the perturbed van der Walls EOS is used. The detailed description of the GRAY EOS is in Ref.[1]. In our calculation, the processing of the liquid-vapor coexisting phase is modified using the Maxwell method.

\section{RESULTS}

In this section we present the calculated results by the computer code DRAM1D. In the calculation, the EOS parameters of aluminum is cited from Ref.[1]. We assume that the irradiation time of the electron beam is $0.12 \mu \mathrm{s}$, the flux history of the radiation source is in isosceles triangle form.

Figure 1 shows the energy deposition profile for an incident fluence of $1 \mathrm{~J} / \mathrm{cm}^{2}$, where $E_{k}$ is the incident electron energy. The different curves in Fig. 1(a) correspond to different energies of electrons, and the different curves in Fig. 1(b) correspond to different incident angles for $1 \mathrm{MeV}$ electrons. From this figure we know that with the increases of incident energy of electrons, the energy deposition depth increases and the profile becomes more smooth. If the incident angle increase, the energy deposition depth decreases, the profile becomes more steep, and the total deposited energy decreases. As an approximation, the total deposited fluence $\Phi_{d}$ is proportional to the fourth root of the cosine of the incident angle $(\theta)$, that is

$$
\Phi_{d}=\Phi_{0} \cos ^{1 / 4} \theta
$$




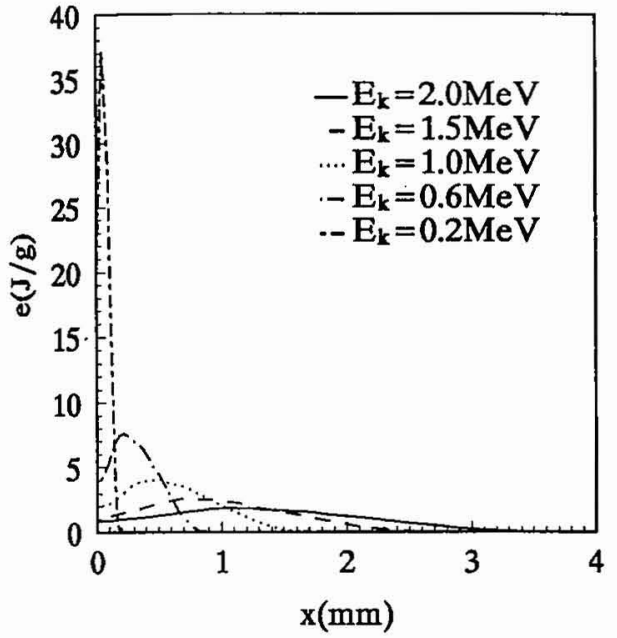

(a)

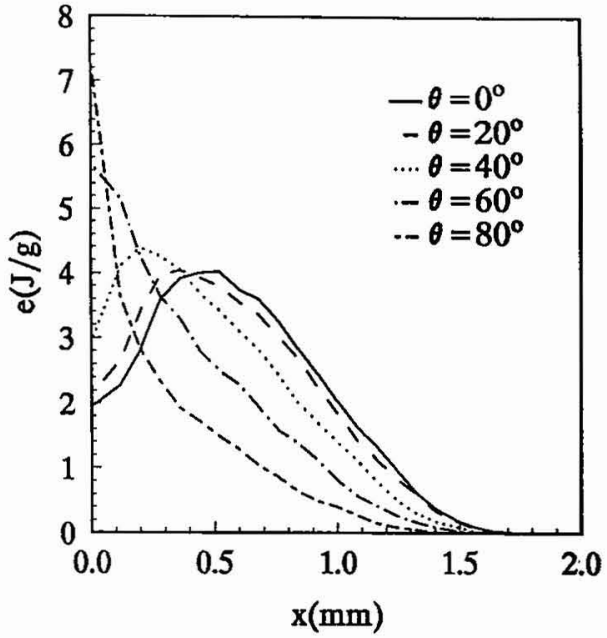

(b)

Figure 1: Energy deposition profiles in aluminum for different electron energies (a) and for different incident angles (b), normalized to $1 \mathrm{~J} / \mathrm{cm}^{2}$ incident fluence, where $E_{k}$ is the incident electron energy

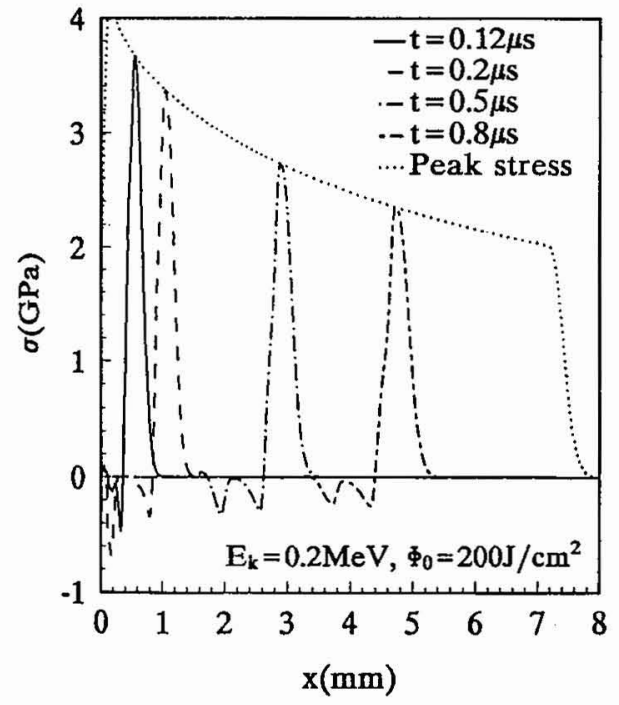

(a)

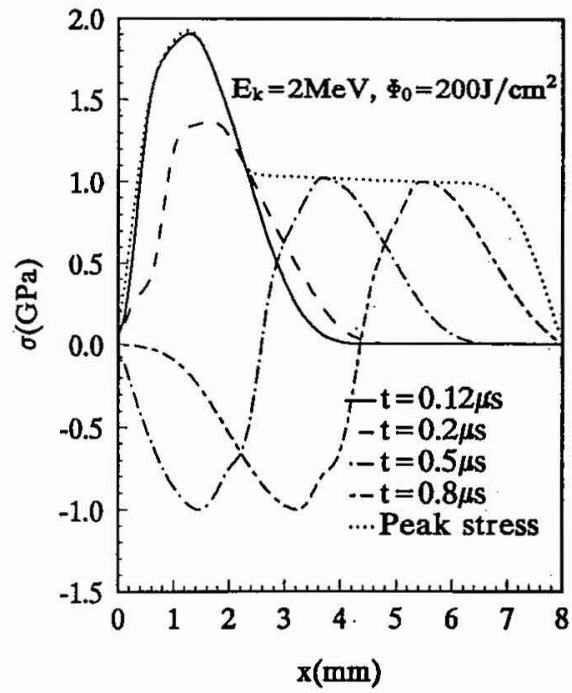

(b)

Figure 2: Propagation of stress wave in aluminum exposed to an incident fluence of $200 \mathrm{~J} / \mathrm{cm}^{2}$ for (a) $0.2 \mathrm{MeV}$ electrons and for (b) $2 \mathrm{MeV}$ electrons 


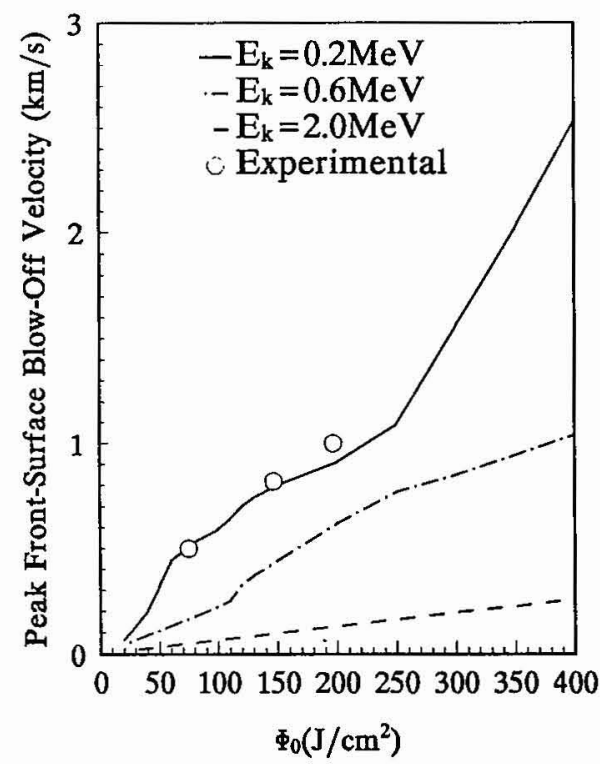

Figure 3: Peak front surface blow-off velocity vs. incident fluence, where the experimental results are cited from Oswald et al. [3] for $0.2 \mathrm{MeV}$ electrons

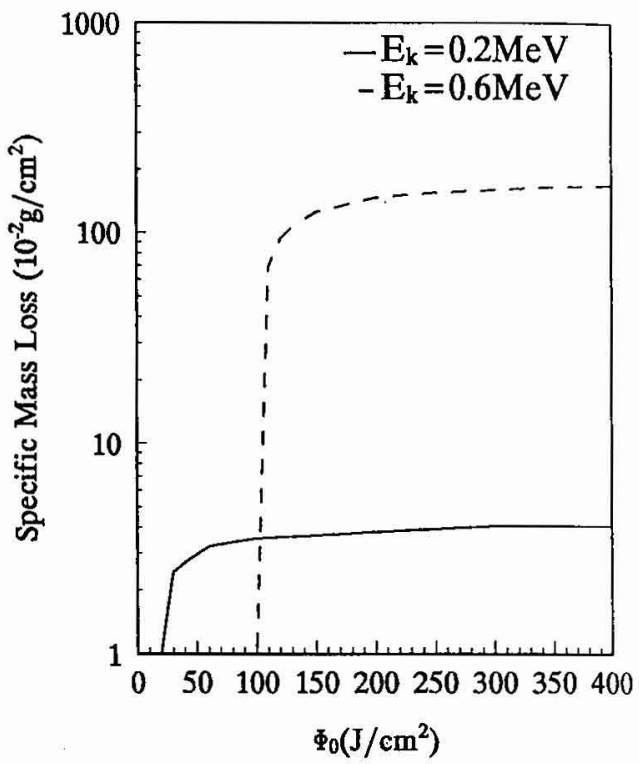

Figure 4: Specific mass loss as a function of incident fluence

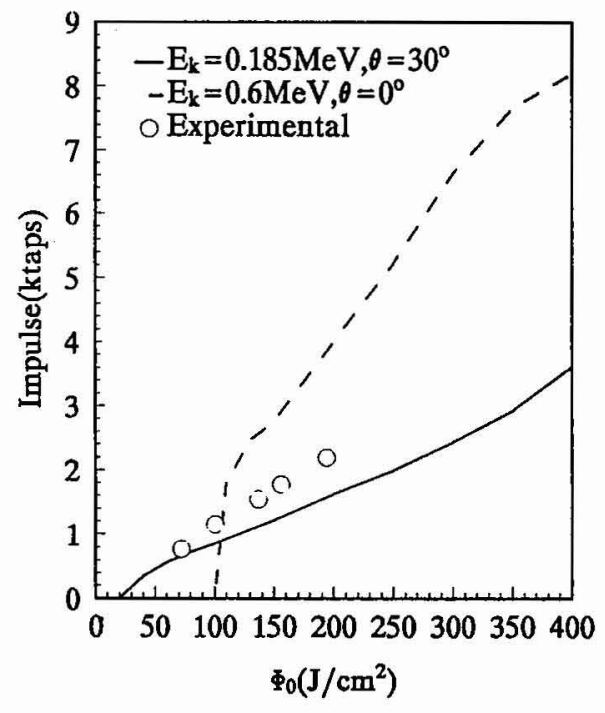

Figure 5: Impulse produced by the exposure of aluminum to a $0.2 \mathrm{MeV}$ pulsed electron beam. The experimental data are cited from Oswald et al. [3] for $0.2 \mathrm{MeV}$ electrons 
where $\Phi_{0}$ is the incident fluence.

The propagation of thermal stress wave for 0.2 and $2 \mathrm{MeV}$ electrons is shown in Fig. 2 at different times. It shows that the stress wave is a compression wave followed by a tension wave. If the electron energy is lower, the duration of the stress wave is narrower, the amplitude of the compression wave is higher while the tension wave is weaker, and the peak stress attenuates faster. In contrast, as the electron energy increases, the compression wave becomes weaker while the tension wave becomes stronger, and the peak stress attenuates more slowly.

Figure 3 shows the peak front surface blow-off velocities as a function of the incident fluence, where the experimental results are cited from Oswald et al. [3]. When the electron energy is high, such as $2 \mathrm{MeV}$, the peak front surface blow-off velocity is small and increases linearly with the incident fluence in approximation. On the contrary, when the electron energy is low, the peak blow-off velocities increase nonlinearly with the fluence. We suggest that this phenomena results from the following reasons: when the electron energy is high enough, the energy deposition depth is very large and the deposition profile becomes very smooth (see Fig. 1), so that the deposited energy near the surface front is not enough to melt the material even the incident fluence is large enough. As the electron energy decreases, the energy deposition profile becomes more steep and the energy absorbed by the front surface material increases, so the surface material will go into melt, liquid or gas state step by step with the increase of fluence. Due to the strong interaction between the atoms of solid, the solid front always moves at low velocities as oscillating form. When the surface material vaporized, it will blow off at a high stable velocity.

The mass loss is presented in Fig. 4 as a function of incident fluence. The calculated data shows the mass loss depends nonliearly on the incident fluence. If we extrapolate the data to zero mass loss, a threshold fluence value will be obtained. The calculated result indicates that the threshold value is strongly dependent on the electron energy. For a given electron energy, with the increase of the incident fluence, the mass loss will quickly approach to an asymptotic value. The calculated data shows the asymptotic value is the specific mass contained in the range of deposition. From Fig. 4 we can also find that both the values of threshold and asymptotic increase with the incident energy of electrons.

Figure 5 is the impulse plotted as a function of incident fluence for two kinds of electron energies $(0.2$ and $2 \mathrm{MeV}$ ), where the experimental results are cited from Oswald et al. [3]. Because the impulse is mainly caused by the blow-off of the ejected material, it seems as if the Fig. 5 came from some combination of Fig. 3 and Fig. 4.

\section{CONCLUSIONS}

The irradiation of aluminum by a pulsed electron beam results in a thermal stress wave which is a compression-tension composite wave. For a given electron energy and a material, only the incident fluence over a threshold value can result in the mass loss, and, with the increases of the incident fluence the mass loss approach to an asymptotic value, which is the specific mass contained in the range of energy deposition. 


\section{References}

[1] Royce E.B. "GRAY, a three phase equations of state", Lawrence Livermore Laboratory, Report No. UCRL-51121,1971.

[2] Berger M.J. Methods in Computational Physics(Academic, New York, 1963) Vol.1,pp.135-215.

[3] Oswald Jr. R.B., McLean F.B., Schallhom D.R. and Oldham T.R., J.Appl.Phys. 44(1973)3563-3574. 